\title{
Evaluation of the Pelvioureteral Function Through a New Urine Bolusmetry : Simultaneous Measurement of Urine Bolus Volume and Electroureterogram
}

\author{
Tadashi Harada, Kazumi Etori, Takumi Kumasaki, \\ Teruaki Kigure, Osamu NishiZawa \\ and Seigi TsuchIDA \\ Department of Urology, Akita University School of Medicine, Japan
}

(Director: Prof. S. Tsuchida.)

\begin{abstract}
Harada, T., Etori, K., Kumasaki, T., Kigure, T., Nishizawa, O. and Tsuchida, S. Evaluation of the pelvioureteral function through a new urine bolusmetry: Simultaneous measurement of urine bolus volume and electroureterogarm. Jap. J. Smooth Muscle Res., 1985, 21 (6), 467-480. — N N N equipment to evaluate the urine transport function of the ureteropelvic system has been developed. Simultaneous measuremtnt of urine bolus volume and electrical activity in the ureter is possible by means of this equipment. A urine bolus volume measuring system, which is based on the heat electrical method, is located in the probe tip, and bipolar electrodes for EMG are located in the stem of the Fr. 4 ureteral catheter.

Two kinds of experiments were performed. One was an examination of the new probe through a pervioureteric model using an infusion pump and Nelatons' catheters of various diameters. The other was an animal experiment. The changes in ureteral peristalsis and urine bolus volume in response to diuretics were examined in mongrel dogs through application of this equipment.

The following results were obtained:

1) There was a logarithmic relation between perfusion flow rate in catheters used as ureteral models and the values of voltage depression measured by the heat electrical method.

2) The urine bolus volume was calculated closely through a formula which had been developed from the model experiments.

3) In animal experiments, the bolus volume increased significantly and a tran-
\end{abstract}

Accepted for publication, October 8, 1985 .

原田 忠, 慨取和美, 熊崎 匠, 木暮輝明, 西沢 理, 土田正義：

秋田大学医学部 泌尿器科学教室, $\mathbf{T} 010$ 秋田市本道 1-1-1 
sient increase in peristalsis was noted after the administration of diuretics although there was no significant change in peristaltic velocity.

4) Some pelvioureteric function parameters, i.e. peristaltic frequency, peristaltic velocity, urine bolus volume, bolume, bolus length and ureteral width, are feasible caluculations.

These results indicate that bolusmetry by using this new probe is a valuable method for evaluation of urine transport function in the pelvioureteric system, and suitable for clinical use as well as animal experiments.

\section{Introduction}

The renal pelvis and ureter have physiological importance. Diseases of the pelvis and ureter should produce a greater disturbance in renal function. The evaluation of ureteropelvic function has been performed by means of radiographic visualization, radioisotope renogram, pressure-flow study by renal pelvic perfusion (Whitaker, R.H., 1973), urometry (Kill, F., 1978) and electroureterogram (Fredericks, C.M., Anderson, G.F. \& Pierce, M.J., 1972 ; Tsuchida, S., 1970). However, by such examination quantitative information on urine transportation could not be aquired accurately. The formation of urine bolus and ureteral peristalsis activity are most impotant in urine transportation. We have raported a new examination "urine bolusmetry" using a Fr. 5 whistle tip ureteral catheter and drop counter, by which urine bolus volume and frequency were measured (Harada, T. et. al., 1983). This examination was suitable for clinical use pre- and postoperatively on patients with congenital hydronephrosis failing urine bolus formation. However, in case of large caliber of ureter or large amount of urine secretion, the drainage of urine through the ureteral catheter is not sufficient, and then it is difficult to acculately measure urine bolus volume.

The equipmrnt used in the above work was composed of a heat electrical flow meter and an electromyogram. Heat electrical bolusmetry is based heheat-conduction method for measuring blood flow rate in tissues developed by Golenhofen, et al. (1963). In urodynamic fields, Lutzyer \& Melchior (1969) reported a uro-rheography for the measurement of endoluminal flow. But some problems, i.e. whether the magnitude of the uro-rheogram reveals the flow rate, the velocity, or the length of urine bolus, were not resolved. In this study we discussed such problems.

\section{Method}

We performed two kinds of experiment. One was an examination of the new probe through a pelvio ureteric model using an infusion pump an Nelation's catheters of various diameter. The other was an animal experiment, the changes in ureteral peristalsis and urine bolus volume in response to diuretics were examined in mongrel dogs through a application of this equipment.

\section{1) Ureteropelvic model experiment}

Nelaton's catheters with diameters of 2, 3, 5, 8 and $10 \mathrm{~mm}$ were connected to an infusion pump (Harverd-955 E). Saline heated at $37^{\circ} \mathrm{C}$ was perfused through the catheters by a infusion 


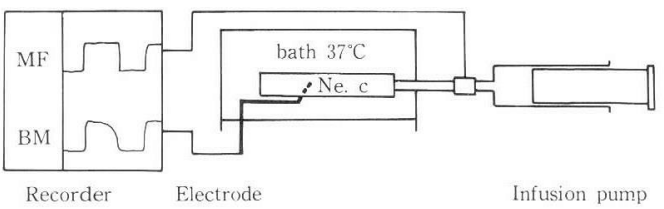

Fig. 1. Schema of the renal pelvic and ureteral model experiments.

MF ; electro magnetic flow meter $\mathrm{BM}$; urine blousmetry Ne. C; Nelaton's catheter

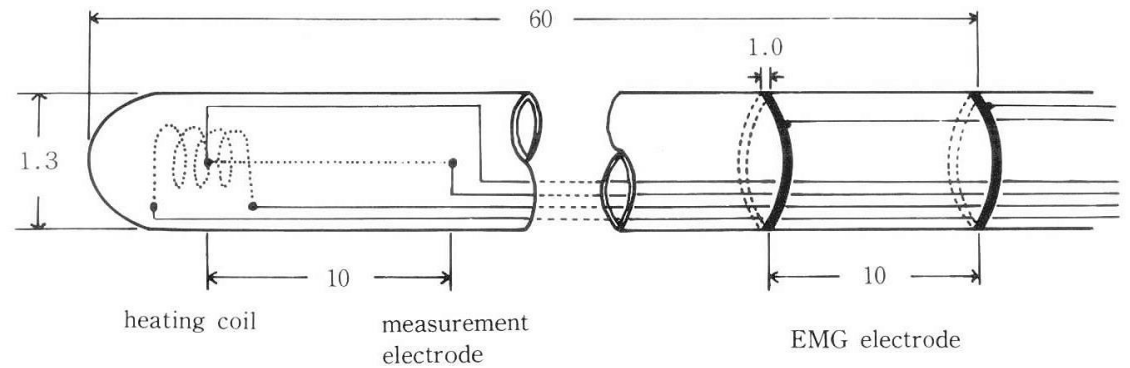

Fig. 2. Electronic components of the urine bolusmetry probe. The heating coil and measurement element are mede of copper (solid line) and constantane (doted line).

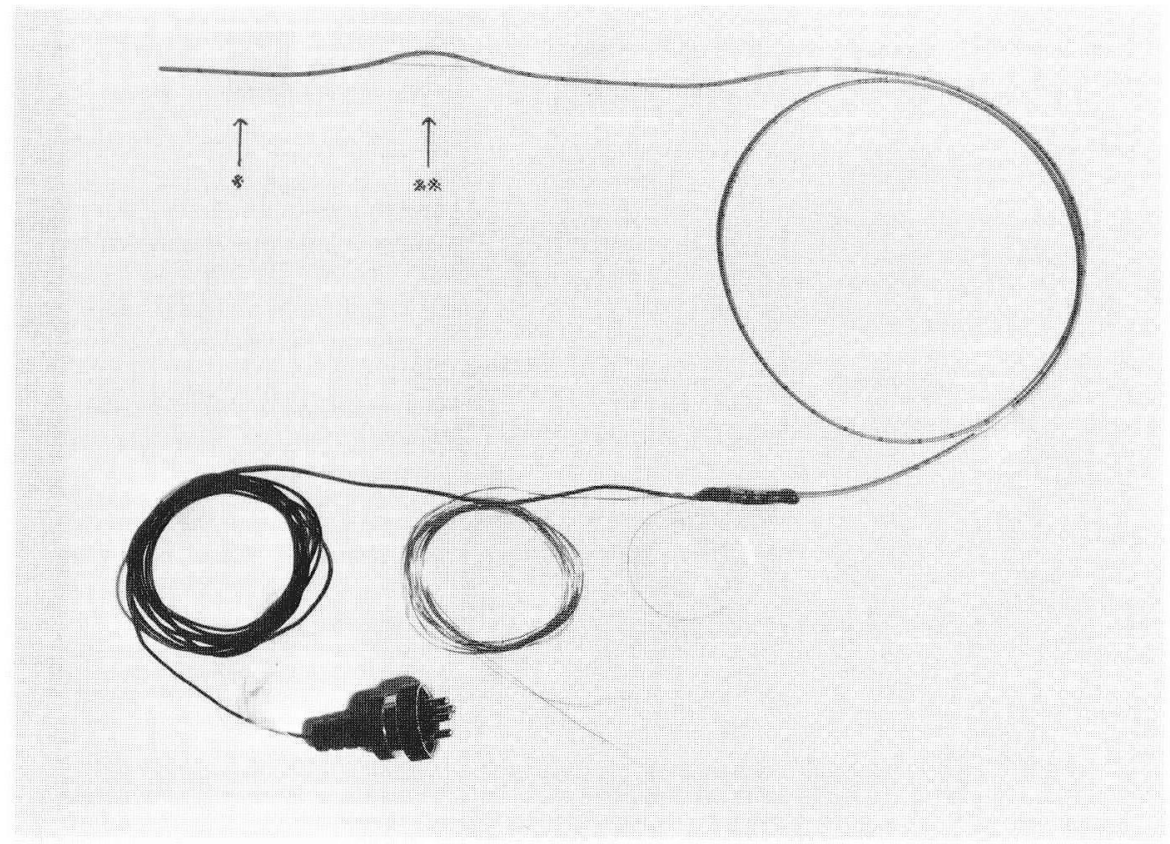

Fig. 3. Photograph of the urine bolusmetry probe.

*; heat electrical usit.

** ; bipolar surface electrode of electroureterogram. The catheter is bended in "U loop" by a pulling the nylon string at the catheter end.

pump which was stired occasionally just as if urine bolus was passed through the ureter.

The urine bolusmetry probe was introduced in to the catheter through small hole which was punched out in the middle portion of the Nelaton's catheter (Fig. 1).

The schema of the probe is illustrated in Fig. 2 and 3. Inside the probe tip, there is a heating coil which is provided with a constant heating current. A thermocouple element of 
copper and constantan is located near the heating coil. The differnce in temperature of the elements of the thermocouple provides a measurememt of the difference in temperature, between the heating element and the surrounding tissue. The heating coil and thermocouple element are mounted in a Fr. 4 ureteral catheter. The electrical resitance of heating coil and

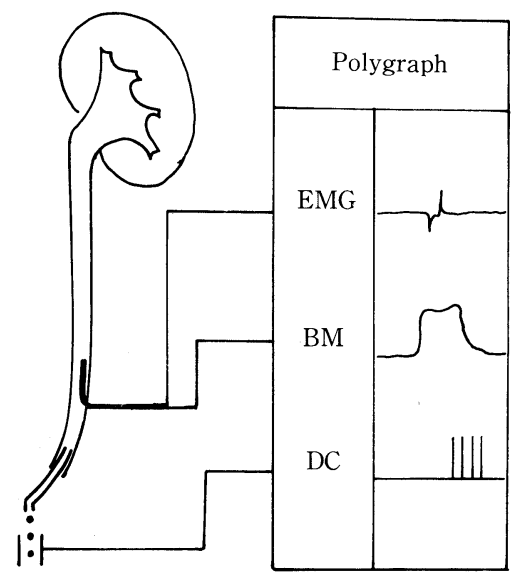

Fig. 4. Schematic drawing of animal experiments. EMG; electroureteromyogram

$\mathrm{BM}$; urine bolusmetry

$\mathrm{DC}$; electric drop counter

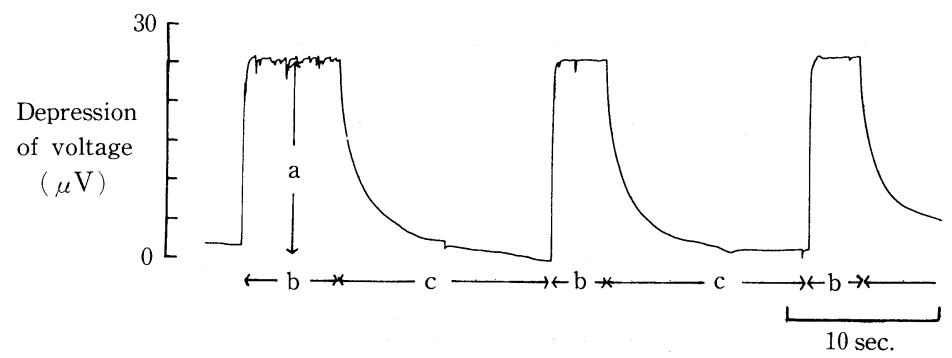

Fig. 5. Voltage depression and catheter perfusion with saline.

Nelaton's catheter with a diameter of $3 \mathrm{~mm}$ is perfused at a rate of $0.1 \mathrm{ml} / \mathrm{sec}$.

a; voltage depression

b; during perfusion

c; without perfusion

TABLE 1. Relation between bolus depression and perfusion flow rate.

\begin{tabular}{c|c|c|c|c|c|c|c|c|c}
\hline \multirow{2}{*}{ Catheter } & \multicolumn{7}{|c}{ Voltage depression of heated thermocouple $(\mu \mathrm{V})$} \\
\cline { 2 - 9 } \multicolumn{2}{c}{} & \multicolumn{7}{c}{ Perfusion flow $\left(\mathrm{cm}^{3} / \mathrm{sec}\right)$} \\
\hline Diameter (cm) & Section $\left(\mathrm{cm}^{2}\right)$ & 0.01 & 0.02 & 0.04 & 0.1 & 0.2 & 0.4 & 0.8 & 2.0 \\
\hline 0.2 & 0.031 & 19 & 23 & 27 & 31 & 34 & 36 & 40 & 43 \\
0.3 & 0.071 & 16 & 20 & 23 & 27 & 30 & 34 & 38 & 42 \\
0.5 & 0.20 & 14 & 20 & 23 & 29 & 32 & 35 & 39 & 42 \\
0.8 & 0.50 & 13 & 17 & 22 & 28 & 32 & 35 & 38 & 40 \\
1.0 & 0.79 & 15 & 18 & 21 & 24 & 28 & 31 & 34 & 38 \\
\hline \multicolumn{2}{|c|}{} & 14.8 & 19.6 & 22.8 & 27.8 & 31.2 & 34.2 & 37.8 & 41.0 \\
& mean & 1.2 & 2.1 & 2.4 & 2.3 & 2.0 & 1.7 & 2.0 & 1.8 \\
\hline
\end{tabular}




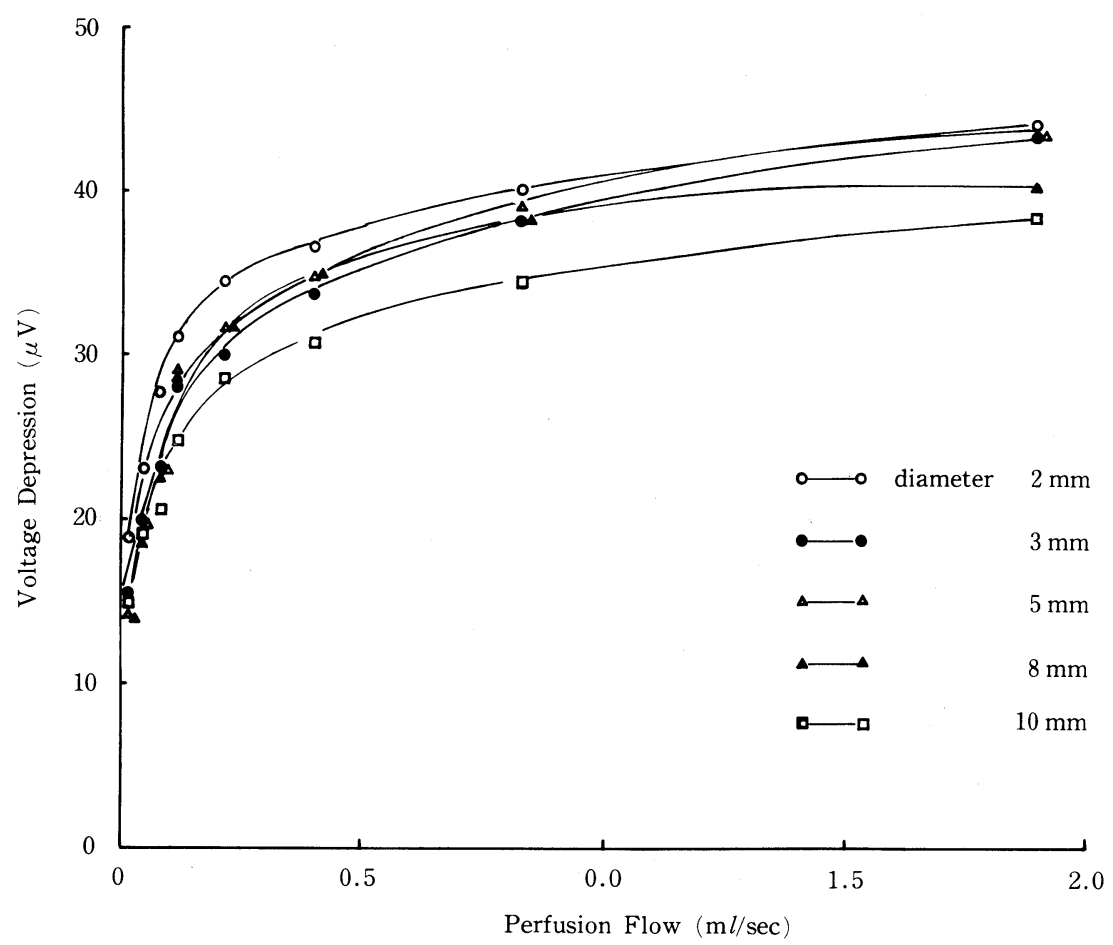

Fig. 6. Relationship between voltage depression and perfusion flow rate in model experiments.

thermocouple were about 20 and $17 \Omega$ respectively.

A "U loop" collar bipolar electrode described previously (Tsuchida, S., 1970) is placed around the catheter $5 \mathrm{~cm}$ away from the thermocouple element (Fig. 2, 3). The gap of the bipolar electrode is $1 \mathrm{~cm}$.

The heating coil was energeized by a constant current of about $35 \mathrm{~mA}$ in order to obtain $80 \mu \mathrm{V}$ in the thermocouple element without perfusion of the catheter. The change of voltage in the thermocouple was measured when the catheter was perfused with saline at a constant flow rate.

The inner diameteres of the catheters examined were 2, 3, 5, 8 and $10 \mathrm{~mm}$. Perfusion flow rates were obtained periodically between 0.01 and $2.0 \mathrm{ml} / \mathrm{sec}$. The correlation between flow rate $\left(\mathrm{cm}^{3} / \mathrm{sec}\right)$ or flow velocity $(\mathrm{cm} / \mathrm{sec})$ and the change of voltage $(\mu \mathrm{V})$ in thermocouple was examined. A U-M meter (Umique-Medical U-M 2000) was used for heating current and voltage measurement.

\section{2) Animal experiments}

Five mongrel dogs weighing between 15 and $18 \mathrm{~kg}$. The dogs were anesthetized with an intravenous administration of sodium pentobarbital $25 \mathrm{mg}$ per $\mathrm{kg}$. The left ureter was exposed by a midline incision and disected at the ureterovesical junction. A new probe for bolusmetry was inserted toward the kidney in the ureter through a small hole $5 \mathrm{~cm}$ above the stump of the cut ureter and a Fr. 5 whistle tip ureteral catheter inserted in the ureteral stump for measurement of urine bolus volume using an electrodrop counter (Fig. 4). 


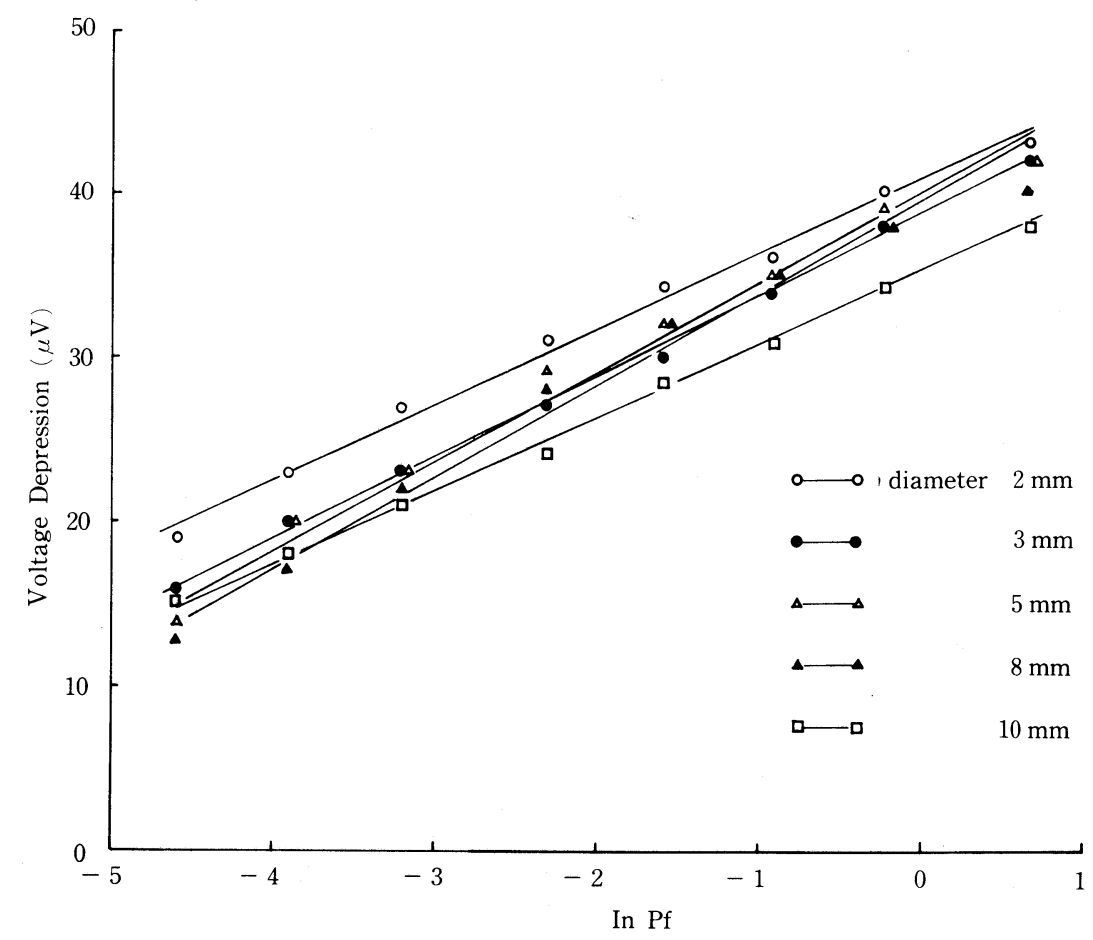

Fig. 7. Relationship between voltage depression and perfusion flow rate in model experments.

$\mathrm{Y}=4.5 \mathrm{X}+40.6, \mathrm{r}=0.996, \mathrm{n}=8$ (diametër ; $2 \mathrm{~mm}$ ).

$\mathrm{Y}=4.9 \mathrm{X}+38.5, \mathrm{r}=0.999, \mathrm{n}=8$ (diameter $; 3 \mathrm{~mm}$ ).

$\mathrm{Y}=5.2 \mathrm{X}+39.7, \mathrm{r}=0.994, \mathrm{n}=8$ (diameter $; 5 \mathrm{~mm}$ ).

$\mathrm{Y}=5.3 \mathrm{X}+39.8, \mathrm{r}=0.988, \mathrm{n}=8$ (diameter ; $8 \mathrm{~mm}$ ).

$\mathrm{Y}=4.4 \mathrm{X}+34.8, \mathrm{r}=0.998, \mathrm{n}=8$ (diameter $; 10 \mathrm{~m}$ ).

$\mathrm{Y}=4.81 \mathrm{X}+38.8, \mathrm{r}=0.970, \mathrm{n}=40$ (total).

Changes in urine bolus volume, peristaltic frequency and peristaltic velocity were mesaured at both the oliguric and diuretic states and then compared. The peristaltic velocity was calculated by the following formula.

$$
\begin{aligned}
& \mathrm{VP}=\mathrm{De} / \mathrm{Dp} \\
& \mathrm{VP}: \text { peristaltic velocity } \\
& \mathrm{De}: \text { electrode distance } \\
& \mathrm{Dp}: \text { duration between the negative and positive main potential }
\end{aligned}
$$

Diuresis was carried out by and intravenous injection of $0.5 \mathrm{mg} / \mathrm{kg}$ furosemide.

\section{Results}

\section{1) Ureteropelvic model experiments}

The voltage in the thermocouple decreased reapidly when the perfusion was started, and stablized in one or two seconds (Fig. 5). When the perfusion was stopped, the voltage increased rapidly, but it tooks about 15 seconds to completely return to the begining voltage.

The time lapse between the decrease and increase in voltage indicated that the catheter was perfused with saline just like the ureter was perfused with urine. 


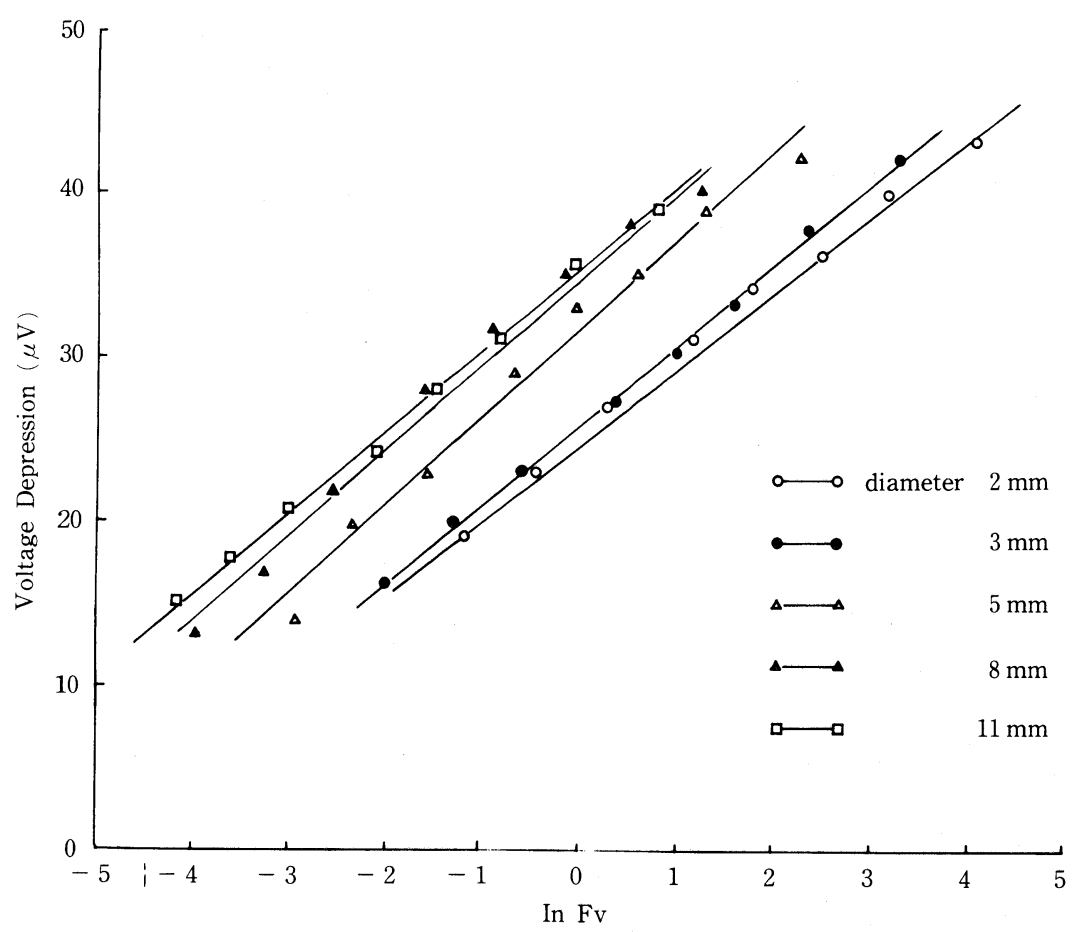

Fig. 8. Relationship between voltage depression and perfusion flow velocity. $\mathrm{Y}=3.7 \mathrm{X}+29.8, \mathrm{n}=40, \mathrm{r}=0.902$ (total)

The change in voltage and perfusion flow rate or flow velocity is shown in Table 1 and Fig. 6. There was a logarithmic relation between these two parameters as illustrated in Fig. 7 and 8. The relationship between the voltage and flow rate or flow velocity for all catheters is expressed as follows.

$$
\begin{aligned}
\mathrm{V} & =4.81 \times \ln \mathrm{Pf}+38.8 \\
\mathrm{r} & =0.98, \quad \mathrm{n}=40 \\
\mathrm{~V} & =3.72 \times \ln \mathrm{Pv}+29.8 \\
\mathrm{r} & =0.90, \quad \mathrm{n}=40 \\
\mathrm{v} & : \text { value of the voltage change } \\
\mathrm{Pf} & : \text { flow rate } \\
\mathrm{Pv} & : \text { flow velocity }
\end{aligned}
$$

The correlation coefficient between voltage and flow rate is higher than the value between voltage and velocity.

Though, the voltage depression followed by perfusion has a small range deviation among different inner diameter catheters (on condition that the diameter of the catheter is under $1 \mathrm{~cm}$ ), the voltage depression is reflected in the flow rate.

\section{2) Animal experiments}

Bolusmtries by heatelectrcal and drop counter method were done on dogs. Electrouretero- 

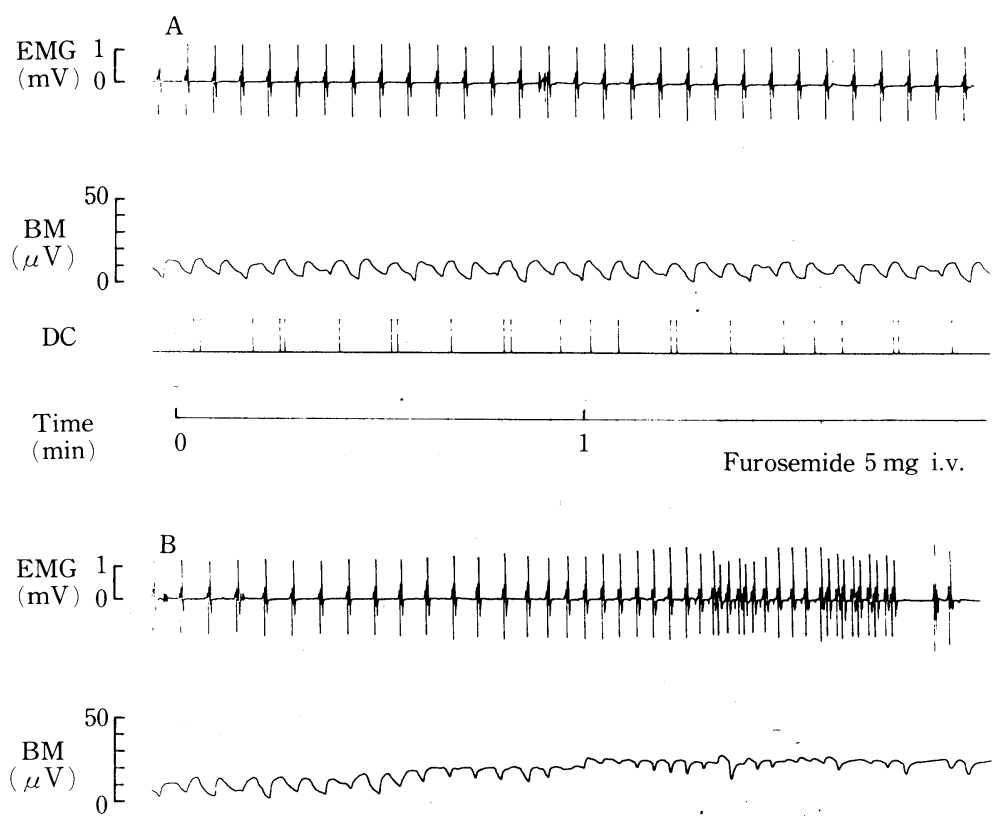

DC

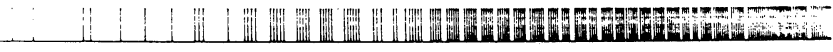

Time

(min)

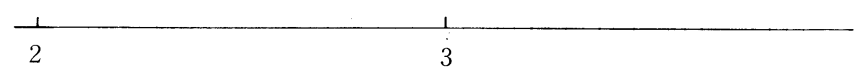

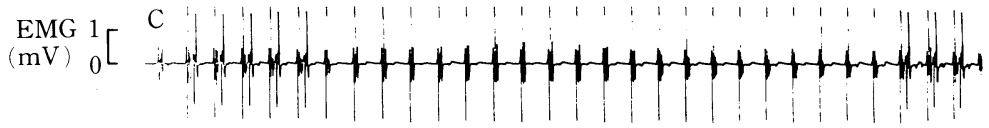

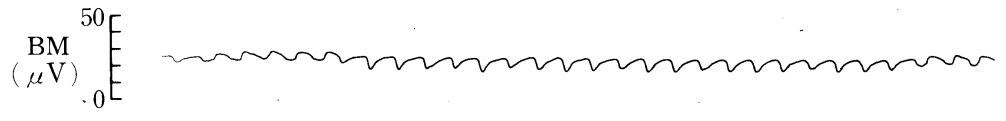

$\mathrm{DC} \quad \mathrm{C}$ -

$\underset{(\min )}{\operatorname{Time}} \frac{1}{4} \quad \frac{1}{5}$

Fig. 9. Urine transport function of the ureteropelvic system (dog No. 5).

EMG; electroureterogram

$\mathrm{BM}$; urine blousmetry

DC; electric drop counter

Elongation of bolus duration, increase on the bolusmetry and increase of peristalsis are noted after administration of diuretics.

grams were read simultaneously (Fig. 9). During the oliguric state, antegrade action potentials were presented regularly at $4.4 \mathrm{sec}$ intervals. The voltage depression in bolusmetry corresponded to the action potentials at a $1: 1$ ratio. The bolus durations were between 0.4 and 1.4 sec. The maximum depression of voltage was 10 or $11 \mu \mathrm{V}$. The bolus volume measured by drop counter was between 0.014 and $0.018 \mathrm{~m} l$. 


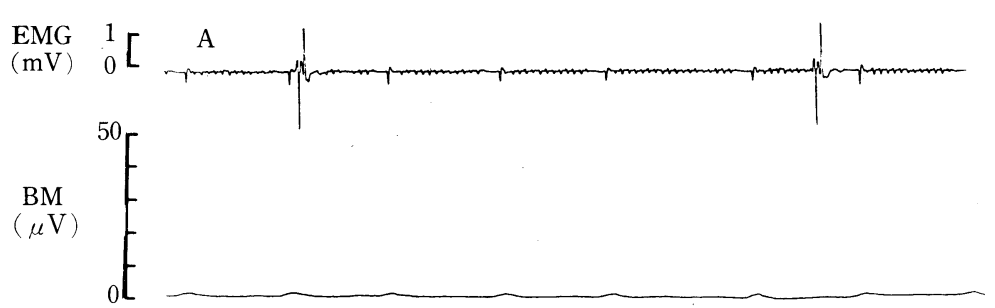

DC

$$
10 \mathrm{sec} \text {. }
$$
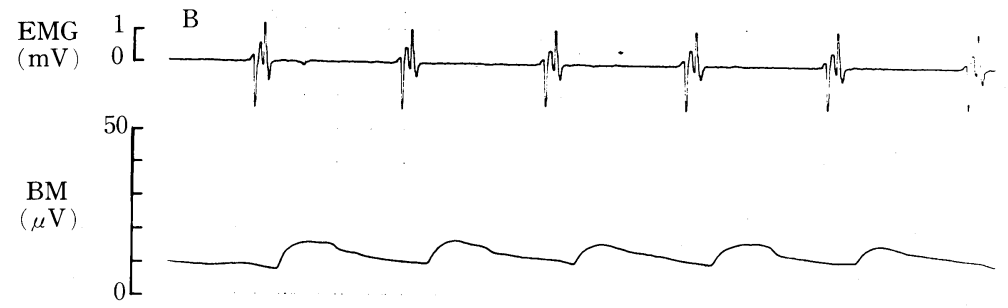

DC
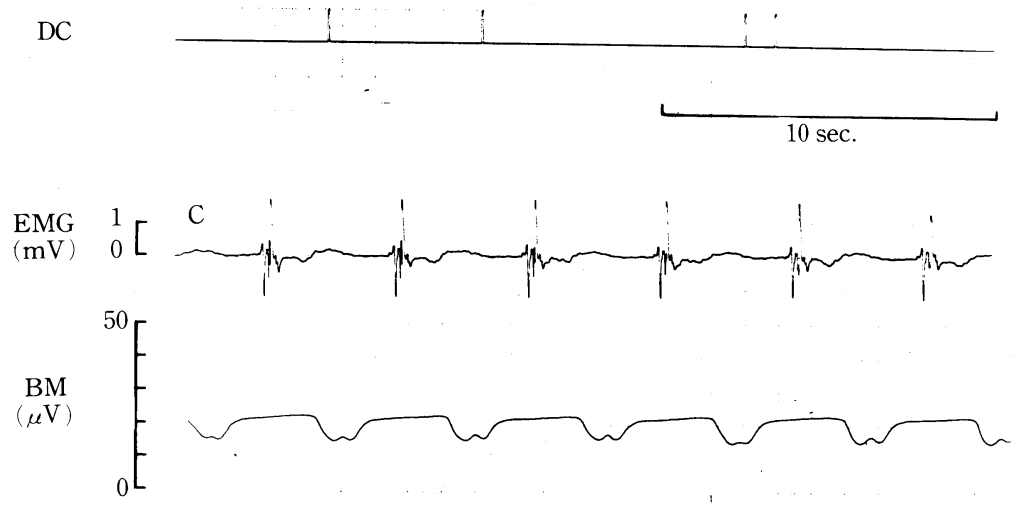

$\mathrm{DC}$

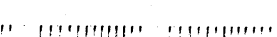

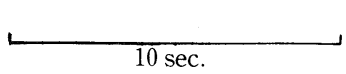

Fig. 10. Urine transport function of the ureteropelvic system (dog No. 4).

A ; during oliguria

$\mathrm{B}$; during moderate diuresis

$\mathrm{C}$; during diuresis

EMG; electroureterogram

$\mathrm{BM}$; urine bolusmetry

DC; drop counter

Two minutes after injection of $5 \mathrm{mg}$ furosemide, the frequency of peristaltic action potential was increased, and the interval of peristalsis was detected. Three minutes after injection, regular peristalsis with a constant interval of $4.1 \mathrm{sec}$ was recorded. Voltage depression increased to 26 or $28 \mu \mathrm{V}$ during the diuretic state, and the duration was prolonged gradually. The bolus volume measured by drop counter increased to about $0.4 \mathrm{~m} l$ (Fig. 10 and 11). 

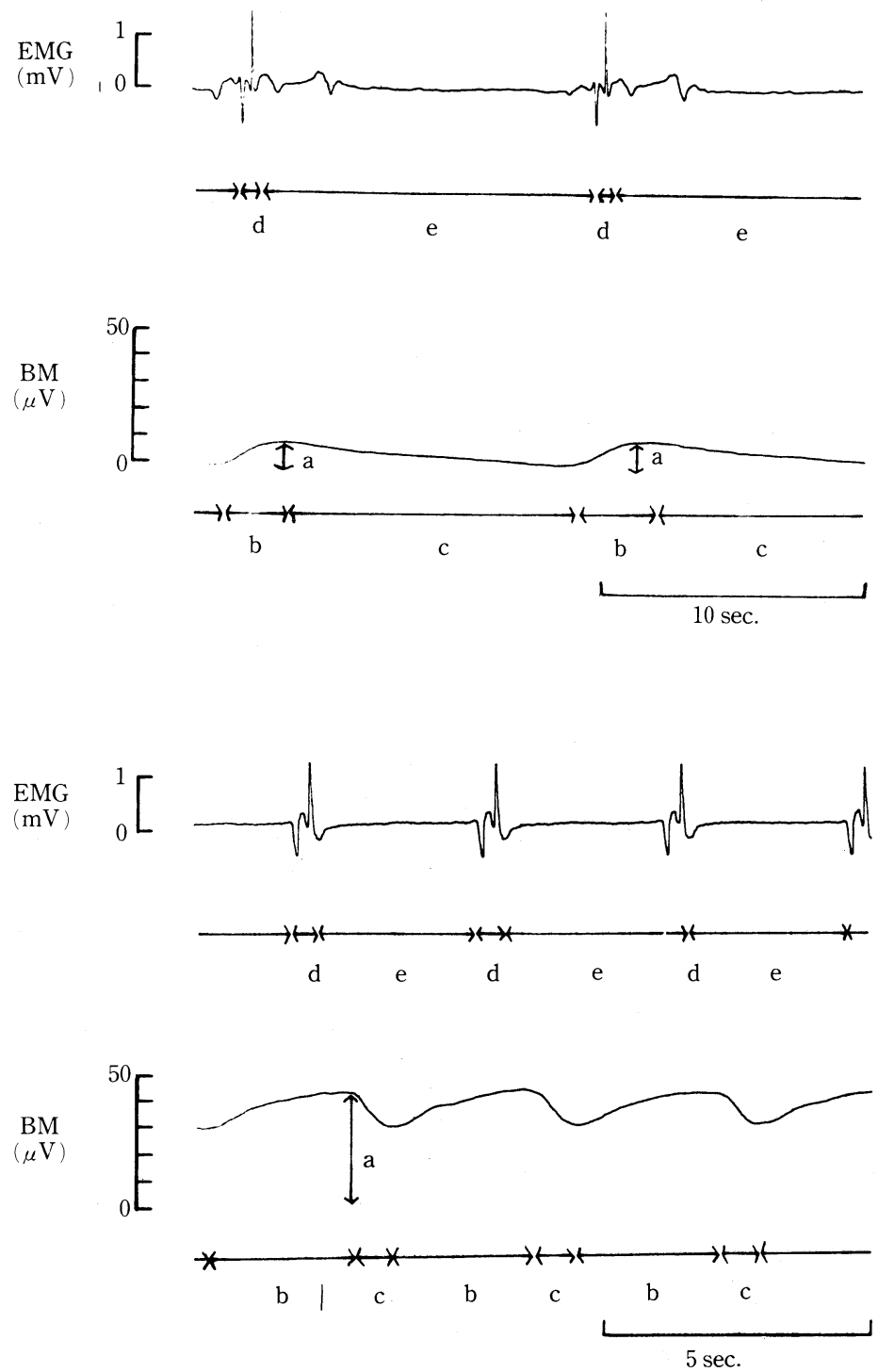

Fig. 11. Urine transport function of the ureteropelvic system (dog No. 3). upper ; during oliguria lower; during diuresis
a ; voltage
$\mathrm{b}$; bolus duration
$c$; interval between urine bovuses
$\mathrm{d}$; duration of discharge
e ; resting interval

We tried to calculate bolus volume from the voltage depression and bolus duration according to the equations obtained from the model experiments. 
TABLE 2. Function of the ureteropelvic system in dog experiments.

\begin{tabular}{|c|c|c|c|c|c|c|}
\hline & \multirow{2}{*}{\multicolumn{2}{|c|}{$\begin{array}{l}\text { Ur in flow } \\
(\mathrm{m} l / \mathrm{min})\end{array}$}} & \multicolumn{2}{|c|}{ Bolus volume $(\mathrm{m} l)$} & \multicolumn{2}{|c|}{$\mathrm{EMG}$} \\
\hline & & & Heat conduction & Drop & Interval (sec) & Velocity $(\mathrm{cm} / \mathrm{sec})$ \\
\hline \multirow{7}{*}{ Oligouria } & (1) & 0.34 & 0.014 & 0.023 & 4.2 & 3.3 \\
\hline & (2) & 0.31 & 0.011 & 0.022 & 4.2 & 3.5 \\
\hline & (3) & 0.12 & 0.0025 & 0.028 & 12.8 & 2.8 \\
\hline & (4) & 0.035 & 0.00031 & 0.0093 & 15.5 & 2.8 \\
\hline & $(5)$ & 0.38 & 0.031 & 0.028 & 4.4 & 3.3 \\
\hline & mean & 0.24 & 0.012 & 0.022 & 8.2 & 3.1 \\
\hline & S.D. & 0.13 & 0.010 & 0.007 & 4.9 & 0.3 \\
\hline \multirow{7}{*}{ Diuresis } & (1) & 5.40 & 0.11 & 0.37 & 4.1 & 4.0 \\
\hline & (2) & 3.42 & 0.20 & 0.22 & 4.0 & 3.2 \\
\hline & (3) & 4.57 & 0.65 & 0.26 & 3.4 & 2.6 \\
\hline & (4) & 1.65 & 0.09 & 0.13 & 4.6 & 2.4 \\
\hline & (5) & 5.85 & 0.58 & 0.40 & 4.1 & 3.3 \\
\hline & mean & 4.18 & 0.33 & 0.28 & 4.0 & 3.1 \\
\hline & S.D. & 1.51 & 0.24 & 0.10 & 0.4 & 0.6 \\
\hline
\end{tabular}

$$
\begin{aligned}
\mathrm{BV} & =\mathrm{b} \times \mathrm{a}^{(\mathrm{a}-38.8) / 4.81} \\
\mathrm{BV} & : \text { bolus volume } \\
\mathrm{a} & : \text { voltage depression } \\
\mathrm{b} & : \text { bolus duration }
\end{aligned}
$$

The mean values of bolus volume were obtained from ten peristalsis, and they are presented in Table 2. During the oligulic state, the values measured by heat electrical method were lower than those by drop counter mothod. To the contrary, however, the values measured by the heatelectrical method were higher than by the drop counter method during the diuretic state.

The interval of peristalsis in the diuretic stated was shorter than that in oliguric state. But, there was no significant difference in the peristaltic velocity between the oliguric and diuretic states.

\section{Discussion}

In the functional examination of the upper urinary tract, several methods have been reported; for instance, observation of urine stream using by cystoscope, cine-radiographic study (Kiil, F., 1978), renal pelvic or ureteral pressure measurement (Kiil, F., 1978), ureteral electromyogram (Fredericks, C.M., Anderson, G.F. \& Pierce, M.J., 1972 ; Tsuchida, S., 1970), Whitaker's test (1973), and measurement of urine bolus stroke volume (Harada, T. et al., 1983 ; Constantinou, C.E., Granoto, J.J. \& Govan, D.E., 1974).

There are some parameters in urodynamic examination of ureteropelvic function i.e. urine flow rate, ureteral pressure, velocity of the urine flow, sectional area of the ureter, volume of the urine volus, length of urine bolus and interval of the peristalsis. Usually without remark- 
able diuresis, urine is transported from the renal pelvis to the bladder by means of urine bolus formation at the site of the ureteropelvic junction and ureteral peristalsis, therefore it is very important to evaluate of urine bolus volume and electric activity of uretral peristalsis. Experimentally, urine bolus volume or urine flow velocity is measured by the ultrasonic doppler technique (Tsuchida, S. et al, 1975), urine drop counting (Harada, T. et al., 1983), magnetic flowmeter or the impedance method. Whitaker's test is recommended in case of detection of upper urinary tract mechanical obstruction. But, there are some minor difficulties in this test, for example, the necessity of invasive nephrostomy, difficulty in detection of fuctional ureteral stenosis (especially in case of huge megaureter (Coolsaet, B.L.E.A., et al., 1980)) and the impossibility of evaluation of ureteral peristaltic activity.

The renal pelvic pressure does not increase if enough urine bolus is made in accordance with the increase of urine secretion. We have reported the results of urine bolus volme mesurement in cases of congenital hydronephrosis by means of urine drop counting (Harada, T., et al., 1983). But it is hard to measure accurately in cases of more excessive urine secretion, or dilated ureter under which conditions urine leakage without passage through the catheter becomes a problem. Urometry is one of procedures to examine the urine bolus and ureteral peristalsis, but it does not show the volume of urine bolus, nor does it always present accurate ureteral pressure as the catheter works to obstruct the ureter (Harada, T., et al., 1983).

Therefore, we have developed new equipment to evaluate urine transport function. Simultaneous measurement of urine bolus volume and electrical activity in the ureter is possible by means of this equipment. Lutzeyer \& Melichow (1969) reported the uro-rheogram which is based on the heat electrical method, but they did not comment precisely on the shape of the wave recorded by uro-rheography. In other words, they did not state whether the amplitude of the wave in uro-rheogram indicates the urine velocity, urine bolus volume or the length of urine bolus.

The heatelectrical method was established by Golenhofen et al. (1963) for measuring blood perfusion rate in tissue. The method is based on the physical principle according to which a heated body loses heat to its surroundings. The heat conduction is, with some limitation, proportionate to the perfusion flow rate of the surrounding medium. The blood perfusion rate of the brain, kidney or gastrointestinal tract was measured by this procedure.

The uretral model experiment was performed using by a catheter typed probe for the measurement of endoluminal flow. The voltage in the thermocouple decreased simultaneously with saline perfusion through the catheter and it increased after perfusion stopped, but the recovery to base line required 15 seconds. The duation from the beginning of the voltage depression to the beginning of the voltage recovery, must indicate the passage time of the urine bolus through the measurement probe. The prolonged recovery time may be shortened by increasing the heating current. But, in clinical use, the temperature will be over the physiological limit if the heating current increases excessively. The voltage of the measurement element generated $42 \mu \mathrm{V}$ in the copper and constantan thermocouple per $1{ }^{\circ} \mathrm{C}$ difference between the 2 points (Hagihara, Y., 1967). In this study, the heating coil was given sufficient current to gain $80 \mu \mathrm{V}$ in the thermocouple, and a catheter temperature of $2^{\circ} \mathrm{C}$ higher than the surrounding tissue resulted. The thermal increase must be within phsiological limits. 
The relationship between voltage change and perfusion flow rate or flow velocity was not liniar as shown in Fig. 6, but, instead, there was a logarithmic relation between these two values with a coefficient of correlation of 0.98 or more. The question remains which does the voltage depression indicate, flow rate or flow velocity in endoluminal flow measuring system. Concerning the model experimentt using several catheters of various diameter, the deviation of the voltage depression at a certain flow rate was smaller than the value at a certain flow velocity. In other words, with the limiting condition that the catheter as a model of the ureter is not so large in diameter, the value of the voltage expreses the flow rate not but flow velocity.

Concerning bolusmetry in animal experiments, the duration between the start of the voltage depression and the begining of the recovery represents the passage time of urine bolus at the site of the electrode. The intensity of the voltage depression indicates urine flow rate. In accordance with the increase of urine secretion after administration of diuretics, the bolus duration was prolonged and the voltage depression showed large amplitude.

It was noticed that peristaltic frequency increased temporally after the administration of diuretics. Constantinou et al. (1974) reported a similar phenomenon. At the maximum urine flow rate, the curve of voltage depression did not recover to the base line. That is to say the sphincteric ring disappeared, and the ureter was filled with the urine column.

Electroureterogram simultaneously recorded with heat electrical flow measurement indicated the peristaltic direction (that is whether normoperistalsis or antiperistalsis), frequency and peristaltic velocity. There were no remarkable changes in peristaltic velocity according to the urine flow increase. It is presumed that the velocity of urine bolus is equal to the peristaltic velocity without severe diuresis. The following parameters in pelvio ureteral urodinamic function are obtained through a new urine bolusmetry.

$$
\begin{aligned}
\mathrm{BV} & =\mathrm{b} \times \mathrm{e}^{(\mathrm{a}-38.8) / 4.81} \\
\mathrm{PV} & =\mathrm{c} / \mathrm{d} \\
\mathrm{BL} & =\mathrm{b} \times \mathrm{PV} \\
\mathrm{UW} & =\mathrm{BV} / \mathrm{BL} \\
\mathrm{BI} & =\mathrm{PI} \\
\mathrm{a} & : \text { voltage depression } \\
\mathrm{b} & : \text { bolus duration } \\
\mathrm{c} & : \text { distance of the bipolar EMG electrodes } \\
\mathrm{d} & : \text { duration of the biphasic discharge } \\
\mathrm{BV} & : \text { bolus volume } \\
\mathrm{BL} & : \text { bolus length } \\
\mathrm{PV} & : \text { peristaltic velocity } \\
\mathrm{UW} & : \text { uretral width } \\
\mathrm{BI} & : \text { bolus interval } \\
\mathrm{PI} & : \text { peristaltic interval }
\end{aligned}
$$

We can evaluate precisely ureteropelvic function, through the obsevation of the changes in these parameters after the administration of diuretics.

This urine bolusmetry catheter has an outer diameter $1.3 \mathrm{~mm}$ (No. 4 French catheter). No 
obstructive ill effect was observed in ureteral function of the experimental dogs. Indications are, therefore, that this examination may be useful clinicaly.

\section{References}

Constantinou, C.E., Granoto, J.J. and Govan, D.E. (1974). Dynamics of upper urinary tract, Accomodations in the rate and stroke volume of ureteral peristalsis as a response to transient alteration in urine flow rate. Urol. Int. 29: 249-253.

Coolsaet, B.L.E.A. et al. (1980). Urodynamic investigation of the wide ureter. J. Urol. 124 : 666-672.

Fredericks, C.M., Anderson, G.F. and Pierce, M.J. (1972). Electrical and mechanical responses of untact canine ureter to elevated intravesical pressure. Invest. Urol. 9: 446-451.

Golenhofen, K., Hensel, H. and Hildebradt, G. (1963). Grundlagen der Wärmeleitmessung, Durchblutungsmessung mit Wärmeleitelementen: 1-16. Georg Thieme Verlag, Stuttgart.

Hagihara, Y. (1967). Method for measuring of cerebral blood flow. J. Chiba Med. 43: 130-140.

Hearada, T. et al. (1983). Urine transport function of the upper urinary tract; estimation of urine bolus volume for patients with congenital hydronephrosis. Jap. J. Urol. 74: 1370-1382.

Kiil, F. (1978). Physiology of the renal pelvis and ureter. In : Campbell's Urology, Forth edition, Vol. 1: $55-86$.

Lutzeyer, W. and Melchio, H. (1969). Aus der Grundlagenforschung, Uro-Rheograhie (Eine neus Methode der HarnfluBmessung in Harnleiter mit Wärmelementen). Urologe 8: 208-211.

Tsuchida, S. (1970). Some factors controlling ureteral peristlsis. Tohoku J. exp. Med. 101: 55-66.

Tsuchida, S. et al. (1975). Method for measuring of ureteral urine flow by ultrasonic Doppler technique. Jap. J. Urol. 66 : 781-784.

Whitaker, R.H. (1973). Methods of assessing obstruction indilated ureters. Brit. J. Urol. 45 : 15-22. 